\title{
LOGÍSTICA DE TRANSPORTES E IMPORTAÇÕES DE MERCADORIAS NO NORTE DE MINAS GERAIS
}

TRANSPORT LOGISTICS AND IMPORTS IN THE NORTH OF MINAS GERAIS

\author{
Luiz Andrei Gonçalves Pereira ${ }^{1}$, William Rodrigues Ferreira ${ }^{2}$ \\ ${ }^{1}$ Universidade Estadual de Montes Claros (UNIMONTES), Montes Claros, MG, Brasil \\ ${ }^{2}$ Universidade Federal de Uberlândia (UFU), Uberlândia, MG, Brasil
}

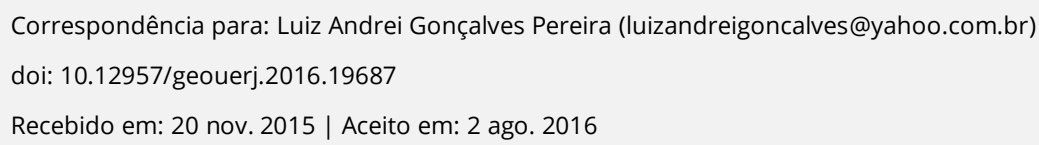

\section{RESUMO}

A ampliação das atividades comerciais no cenário econômico internacional tem elevado a demanda por serviços especializados de logística de transportes para planejar, gerenciar e controlar os fluxos de bens nos diversos mercados espalhados no espaço geográfico. O objetivo foi analisar as interações espaciais entre o norte de Minas Gerais e os mercados internacionais, por meio da configuração territorial dos setores importadores, das modalidades de transportes e dos recintos alfandegados que movimentaram os fluxos de mercadorias, no período de 2001 a 2012. Os procedimentos metodológicos adotados foram à revisão de literatura, as coletas e as análises dos dados de fontes secundárias para a explicação dos fluxos das importações. A logística de transportes utilizada na movimentação das mercadorias importadas foi organizada em uma rede de serviços constituída de transportes internacionais, de recintos alfandegados e de transporte nacional.

Palavras-chave: Logística de transportes. Importações. Mercadorias.

\begin{abstract}
The expansion of trade in the international economic environment has increased the demand for specialized transportation logistics services to plan, manage and control the flow of goods in different markets spread in geographic space. The aim was to analyze the spatial interactions between the north of Minas Gerais and international markets, through the territorial configuration of importing sectors, modes of transport and customs areas that moved the flow of goods in the period 2001-2012. The adopted methodological procedures were the literature review, the collection and analysis of data from secondary sources, to explain of the import flows. The transport logistics used in the movement of goods imported was organized in a service network consisting of international transport, customs areas and national transport.
\end{abstract}

Keywords: transport logistics. Imports. Goods.

\section{INTRODUÇÃO}

A logística pode ser classificada como uma atividade do setor de serviços, que foi incorporada ao mundo dos negócios empresariais pelo desenvolvimento de estratégias que resultaram no processo de planejamento e de gestão para viabilizar a organização e a operacionalização dos fluxos de matériasprimas, de bens semiacabados e de peças de montagem (reposição) destinados à armazenagem e às linhas de produção. Depois dos produtos prontos, os serviços de logística organizam os fluxos das 
mercadorias que são levadas para armazéns, depósitos e/ou lojas de clientes para serem comercializados, distribuídos e consumidos. Além dos serviços de suprimentos, de produção e de distribuição, a logística organiza uma linha de serviços reversos para que os resíduos e os produtos defeituosos possam retornar aos fabricantes.

A ampliação das atividades comerciais no cenário econômico internacional tem elevado a demanda por serviços especializados de logística de transportes para planejar, gerenciar e controlar os fluxos de bens na cadeia de suprimentos, de produção e de distribuição de mercadorias exportadas e importadas por agentes residentes em diversos mercados espalhados no espaço geográfico. Desta forma, este estudo buscou responder a seguinte questão: como está organizada a logística de transportes que articula espacialmente os fluxos de mercadorias importadas do exterior por empresas e/ou setores localizados no norte de Minas Gerais? Este artigo tem como objetivo analisar as interações espaciais entre o norte de Minas Gerais e os mercados internacionais, por meio da configuração territorial dos setores importadores, das modalidades de transportes e dos recintos alfandegados que movimentaram os fluxos de mercadorias, no período de 2001 a 2012.

Os procedimentos metodológicos utilizados foram à revisão de literatura com o intuito de sustentar as discussões de temáticas e/ou de conceitos referentes à logística de transportes, comércio internacional e importações de mercadorias. Essas abordagens foram entrelaçadas com as coletas e as análises de dados secundários, disponibilizados pelo Ministério do Desenvolvimento, Indústria e Comércio Exterior - MDIC - na plataforma online ALICEWEB2, mostrando as interações espaciais dos fluxos de mercadorias importadas, por subsetores econômicos, que circulam por meio da logística de transportes internacional e nacional.

Os agrupamentos dos dados em categorias setoriais permitiram a elaboração de mapas temáticos através da utilização do software Arcgis 9.3 que mostram a espacialização da logística de transportes internacional, dos recintos alfandegados e do transporte nacional utilizados na movimentação de mercadorias importadas por empresas/setores, com domicílios fiscais, na região norte de Minas Gerais. 
Além disso, os países de origem dos produtos importados por norte-mineiros foram agrupados em blocos econômicos regionais, que são União Europeia; Acordo de Livre Comércio da América do Norte (NAFTA); Cooperação Econômica da Ásia e do Pacífico (APEC), excluso os países do NAFTA; Mercado Comum do Sul (MERCOSUL) e outros blocos econômicos/países.

\section{A logística e os negócios empresariais: uma abordagem geográfica}

Espacial e territorialmente, a logística depende da eficiência e da confiabilidade das infraestruturas e dos serviços existentes para promover a organização dos serviços de transportes, de armazenagem, de transbordos e de comunicações/ informações, que são os principais responsáveis pela otimização e pela operacionalização dos fluxos de mercadorias. Para explicar a organização atual da logística aplicada em diversos segmentos empresariais, os autores Rocha (2001), Rodrigues (2003), Ballou (2006), Monié (2011) e Christopher (2011) reconhecem, em suas abordagens, que o período pós Segunda Guerra Mundial é uma referência para o desenvolvimento da logística moderna, na medida em que a logística torna-se uma atividade de serviços vital para que as organizações empresariais possam conquistar vantagens competitivas nos diversos mercados nacionais e internacionais.

Nesses mercados, considerando os serviços logísticos disponíveis para empresas e consumidores, Monié (2011) destaca a logística como um instrumento de planejamento, de organização, de gestão e de estratégias que as empresas utilizam para prestar serviços, elaborar e comercializar mercadorias, sendo necessária a gestão dos fluxos materiais (bens) e imateriais (informações) para coordenar, de forma sincronizada, a oferta e a demanda de bens e de serviços entre consumidores, fornecedores, produtores e operadores de distribuição. No sistema de produção e de comercialização, Ballou (2006), David e Stewart (2010) apontam a ocorrência de fluxos em cadeia, que envolve a compra de matériasprimas, de produtos semiacabados, de equipamentos e de peças para a linha de produção ou de montagem, bem como a produção, a venda e a entrega do produto final ao cliente. 
A logística deve ser vista como algo que representa a prestação de serviços, desenvolvendo as estratégias no processo de planejamento e de gestão para promover a articulação espacial de forma sincronizada entre as diversas bases de infraestruturas e os fluxos de bens materiais e imateriais no mundo dos negócios. Corroborando os argumentos anteriores, Silveira (2009) e Silveira (2011) destacou que a logística não é uma infraestrutura (fixo) e também não é um sistema de movimento (fluxo), pois a logística é uma atividade do setor de serviços que desenvolve as estratégias, o planejamento e a gestão, principalmente dos transportes, do armazenamento e das comunicações.

A logística participa das transformações dos circuitos produtivos e dos círculos espaciais de cooperações comerciais ao desenvolver estratégias para conquistar mercados e reduzir custos operacionais das empresas. Por isso, o planejamento e a gestão na logística resultam em agilidade na movimentação de produtos, de serviços e de informações de forma rápida e segura para que uma empresa possa acelerar a circulação do capital e garantir uma maior lucratividade na concorrência intercapitalista. Para ter um bom desempenho, a logística incorpora as tecnologias disponíveis como forma de auxiliar o planejamento e a gestão das atividades no âmbito público e privado (SILVEIRA, 2011). No mercado, as empresas e os consumidores buscam serviços logísticos eficientes, confiáveis e de baixo custo, e com isso o planejamento, a gestão e a operacionalização da logística tornam-se um grande desafio para os setores públicos e privados.

Os setores públicos e privados usam as tecnologias de informações para planejar e gerenciar o desempenho da logística com o intuito de melhorar a infraestrutura e os serviços logísticos, visando agilizar os fluxos de bens materiais e imateriais de forma rápida, segura, confiável e de baixo custo nas trocas comerciais. Neste sentido, Novaes (2001) explica a logística como um conjunto de atividades humanas, materiais, tecnológicas e de informações, visando à eficiência e às melhorias dos níveis dos serviços prestados. Por outro lado, a competição acirrada entre as empresas tem levado à redução contínua dos custos logísticos na prestação de serviços para a movimentação de mercadorias. 0 desafio da logística é fazer uma associação entre a redução de custos e a garantia da qualidade dos serviços prestados. 
A logística torna-se relevante na prestação de serviços, uma vez que promove as inter-relações das empresas, dos clientes, dos fornecedores e dos prestadores de serviços, aumentando a disponibilidade de produtos e de serviços nos lugares e nos momentos em que são desejados. Ela é uma atividade de serviços que dá vitalidade ao sucesso no mundo dos negócios, mas torna-se necessário destacar que os serviços de logística têm um custo no valor final do produto. Esses custos são mais significativos, principalmente naqueles produtos de baixo valor agregado, como é o caso das commodities. Por isso, o planejamento e a gestão da logística busca reduzir os custos sem comprometer a qualidade dos produtos e dos serviços prestados. Além dos custos, também é preciso levar em consideração a disponibilidade, o desempenho operacional e a confiabilidade dos serviços logísticos (BOWERSOX; CLOSS, 2001). As atividades empresariais demandam confiabilidade no planejamento e na gestão dos serviços logísticos, tornando-os eficientes, seguros e de baixo custo para a viabilização dos fluxos de mercadorias nas trocas comerciais.

O desenvolvimento da logística mostra a evolução do nível de serviços a partir das estratégias, que realizam o planejamento, a gestão e o controle nas formas de produzir, de armazenar, de transportar bens e de comunicar no atendimento das demandas de consumo, onde o foco central é o cliente (consumidor). Para compreender o papel desenvolvido pela logística no sistema fordista e toyotista (pós-fordista) de produção e de consumo flexível. Os autores Harvey (1989) e Castells (1999) destacam que a transição do fordismo para o pós-fordismo foi caracterizada pela passagem da sociedade industrial para uma sociedade de serviços.

As mudanças e as transformações na operacionalização da logística para atender as demandas de consumo e de produção flexível, tendo como foco o consumidor (cliente) que é o agente responsável pela geração de demanda dos fluxos entre a rede de fornecedores, de produtores, de prestadores de serviços e de comerciantes. Esse processo é explicado por Harvey (1989) e por Monié (2011) ao destacar que, no período pós Segunda Guerra Mundial, o fordismo ampliou as relações econômicas através da expansão e da organização do sistema capitalista de produção, na medida em que as 
corporações passaram a exigir uma interação espacial que estimulava a intensificação da produção e do consumo em massa. O sistema fordista de massificação da produção e do consumo ocorreu por meio da articulação das ações estatais, que desenvolveram novos papéis e novos poderes institucionais na dinâmica econômica e social pelos investimentos públicos e privados. 0 fordismo garantiu a lucratividade em um período de expansão da produção, do consumo e do pleno emprego, que perdurou do pós-guerra até por volta de 1973.

No início dos anos de 1970, o surgimento da crise econômica resultou em uma (re) estruturação na forma de produzir e de consumir no cenário econômico mundial. Na análise desse período, Harvey (1989) e Monié (2011) pontuaram que a recessão econômica vivenciada pelo mercado trouxe incertezas, agravando e esgotando o sistema fordista. Uma das saídas para a crise resultou na transição rápida do sistema fordista para o sistema toyotista ou pós-fordista de produção e de consumo, no qual a flexibilidade desenvolveu um conjunto de estratégias para a acumulação de capital.

A acumulação flexível questionou a rigidez da estrutura fordista e implementou a flexibilização da produção, do trabalho, dos produtos e dos padrões de consumo. No sistema toyotista, a inovação tecnológica possibilitou o desenvolvimento de novos produtos em pequenos lotes, em pequena escala e em grande diversidade para atender às demandas na ponta do consumo. Para isso, o acesso e o controle de informações precisas e atualizadas permitiram a articulação na análise instantânea dos dados, que coordenam, de forma centralizada, os interesses corporativos descentralizados sobre a variação da taxa de câmbio e de mudanças de modas para garantir a competitividade das grandes corporações em mercados dispersos espacialmente (HARVEY, 1989). No mercado, a produção flexível ocorre a partir das demandas do mercado consumidor.

No toyotismo, o mercado é atendido a partir da demanda, chamada de produção puxada. Segundo Ohno (1997), a produção ocorre conforme a demanda real do mercado, uma vez que o pedido é feito e enviado à empresa para dar início ao processo de produção, pois a quantidade produzida precisa ser igual à quantidade demandada para ter a eliminação da superprodução, e, consequentemente, a redução 
dos desperdícios e dos custos, começando pela redução dos estoques. Os estoques de matérias-primas e de produtos acabados são considerados desperdícios no mundo dos negócios e podem ser utilizados somente em pequenas quantidades para atender às demandas inesperadas.

No sistema fordista e toyotista, as diferenças estão nas estruturas de produção e de consumo, mas é importante frisar que, nos dois, existe o processo de (re) produção de capital. Para fazer uma diferenciação entre o fordismo e o toyotismo, Antunes Junior, Kliemann Neto e Fensterseifer (1989) caracterizam o fordismo com base no just in case, que desenvolve estratégias de mercado pautadas no sistema de produção tradicional, buscando conquistar novos mercados por meio da redução de custos, organizando uma linha de produção rígida, subdividida em seções fixas, resultando na fabricação de grandes lotes - denominados de lotes econômicos - e constituindo a formação de estoques para maximizar e otimizar a rentabilidade dos meios de produção. A programação da produção ocorre a partir da previsão das vendas, pois a operação realizada empurra a produção de acordo com a previsão de vendas e a formação de estoques de matérias-primas e produtos acabados.

A caracterização do toyotismo feita por Antunes Junior, Kliemann Neto e Fensterseifer (1989) apontou o surgimento do just in time como uma forma de dar resposta às flutuações do mercado, tendo como orientação atender às demandas a partir do consumo. A implantação just in time propaga a oferta de produtos diversificados disponíveis em pequenos lotes com elevado padrão de qualidade e também a redução dos custos de produção para permitir uma maior circulação capital através da eliminação de perdas com estoques, tempo de espera e máquina parada. A produção em decorrência da demanda do mercado pressupõe que, após a confirmação do pedido, inicia-se o seu processo de fabricação, sendo necessária a flexibilização da produção, do consumo e da mão de obra. A produção é puxada pelo consumo e isso acaba reduzindo a necessidade de grandes estoques, uma vez que, no sistema de produção e de consumo just in time busca-se o estoque zero.

O desafio do just in time é articular, sincronizar e conectar os elos em um grande número de processos envolvidos, pois qualquer falha pode complicar a produção e atrasar a entrega do produto ao 
consumidor final (OHONO, 1997). Na estrutura de consumo e de produção, o bom desempenho do just in time está atrelado à articulação dos diversos serviços logísticos disponíveis no mercado e também à qualidade/quantidade da infraestrutura operacional. Mas qualquer empecilho na operacionalização da infraestrutura logística compromete o andamento dos fluxos de mercadorias no espaço geográfico.

A logística tem um papel muito relevante na oferta de serviços para organizar espacialmente a atividade de consumo, de produção e de circulação de mercadorias. De forma resumida, pode ser dito que, no fordismo, a produção era empurrada, uma vez que o produto era fabricado, estocado e aguardava nos estoques/lojas os clientes para comprá-los. Já no toyotismo, a produção é puxada pela demanda, pois o produto, primeiramente, é vendido e depois tem a movimentação de matérias-primas e de produtos semiacabados para fabricá-lo e entregá-lo ao cliente.

A logística tornou-se um serviço precioso na organização do mundo dos negócios. Desta forma, no toyotismo, a administração e o gerenciamento da produção seguem da jusante (consumidor) para a montante (fornecedores) por meio da sincronização da circulação de fluxos materiais e de informacionais, possibilitando oferecer um produto final, considerando e respeitando os prazos de entrega. No processo de distribuição de mercadorias, a logística precisa oferecer serviços de qualidade, uma vez que ela tem a função estratégica de melhorar a qualidade do produto e dos serviços prestados em um ambiente competitivo, que, constantemente, busca a redução de custos (MONIÉ, 2011). Nesse contexto da competitividade, levando em conta a qualidade dos serviços e a redução dos custos logísticos, o que vem a ser logística?

Ao desenvolver o conceito de logística, Novaes (2001) e Larrañaga (2008) assumiram a definição feita pelo Conselho de Gestão da Logística, que a definiu como um processo de planejamento, de gerenciamento e de controle dos fluxos e da armazenagem, de forma eficaz e eficiente, para otimizar os custos de bens, os serviços e as informações em uma cadeia, envolvendo a linha de produção (origem) até o mercado consumidor (consumo). Esse processo garante o suprimento na quantidade certa, de forma adequada e íntegra a um custo razoável no momento exigido, tendo como foco atender às 
exigências dos clientes, que são os agentes que compram e que geram a demanda para a fabricação do produto; por conseguinte, existe a necessidade da organização dos fluxos. Novaes (2001) e Rocha (2001) acrescentaram ao conceito de logística o processo de organização dos fluxos reversos de materiais, os quais se iniciam no ponto de consumo e terminam nos pontos de origem. Os serviços de pós-vendas são voltados para o retorno ao fabricante de produtos com prazo de validade vencido, de resíduos, o retorno de embalagens (incluindo contêineres); e a devolução de produtos, principalmente produtos defeituosos, ao fabricante e varejista ou empresas terceirizadas designadas para recebê-los.

A logística encontra-se subdividida em nacional e internacional (global), Bowersox e Closs (2001) destacam que a logística nacional está concentrada na prestação de serviços em um ambiente que pode ser controlado. A logística global deve atender aos requisitos dos países no exterior em um contexto de grandes incertezas no tocante a distância, à demanda, à diversidade e à documentação das operações. Apesar da complexidade da logística internacional, ela também deve estar bem articulada à logística nacional.

Nessa mesma linha de discussão anterior, os autores David e Stewart (2010, p. 25) conceituaram a logística internacional como "o processo de planejar, implementar e controlar o fluxo e a armazenagem de mercadorias, serviços e informações a elas relacionadas, do ponto de origem ao ponto de consumo, localizado em outro país". A logística internacional é responsável pelo planejamento e pela gestão dos serviços das "atividades inerentes ao movimento de mercadorias e documentos de um país para outro e atividades básicas das operações de exportação e importação" (DAVID; STEWART, 2010, p. 25). A logística internacional deve ser planejada e gerenciada pelos serviços que articulam os fluxos de bens no espaço geográfico nacional e internacional, incluindo também os serviços burocráticos existentes além das fronteiras.

A logística no espaço geográfico nacional e/ou internacional promove a articulação e a organização espacial dos serviços, denominados por Ballou (1993) como atividades primárias e atividades de apoio da logística. As atividades primárias são: os transportes, a manutenção de estoques e o processamento 
de pedidos. Esses três tipos de serviços contribuem com a maior parcela do custo logístico, uma vez que coordenam o nível dos serviços e o cumprimento das tarefas na logística. As atividades de apoio dão suporte para as atividades primárias e são constituídas de armazenagem, manuseio de materiais, embalagem de proteção, proteção, programação de produtos e manutenção de informações. Além das atividades primárias e de apoio apresentadas na discussão anterior, Larrañaga (2001) e Rodrigues (2003) explicitam também outras atividades de serviços importantes no processo de planejamento e de gerenciamento da logística, tais como as compras/suprimentos, a disposição de refugos, o faturamento, a gestão de inventários, a localização industrial, a localização das fazendas, a logística reversa, a previsão de demandas, os serviços ao cliente, o suporte de peças e a comercialização.

Ao considerar a organização da logística, com base em uma discussão mais geográfica entre as empresas, os fornecedores e os clientes, Monié (2011, p. 152) pontua que:

As interações espaciais intensificaram em todas as escalas, pois as redes produtivas integram um número crescente de fornecedores e clientes espalhados no arquipélago econômico mundial. A competitividade decorre doravante menos da simples adição das operações num universo funcionalmente segmentado e cada vez mais da capacidade de organizar este complexo sistema de inter-relações materiais e imateriais.

Em uma estrutura espacial da produção em rede, que tem como suporte os fornecedores e os prestadores de serviços interconectados para atender as demandas dos consumidores. O transporte torna-se um serviço logístico mais visível pelo fato de movimentar bens materiais (mercadorias) produzidos em pontos estratégicos no espaço geográfico. Na logística, Ballou (1993) destaca que o transporte é a atividade logística mais importante na medida em que pode absorver de um a dois terços dos custos logísticos. De alguma forma, a empresa precisa do transporte para movimentar suas matérias-primas ou produtos acabados, pois é impossível a movimentação de bens materiais sem utilizar os meios de transportes. A operacionalização dos serviços de transportes realiza os fluxos materiais entre os diferentes lugares e, com isso, exigem o uso de veículos e de roteiros estabelecidos, obedecendo às regras e à capacidade dos veículos para movimentar mercadorias intra e interempresas. 
No próximo item, o foco de discussão é a logística de transportes utilizada na movimentação de bens e de serviços no espaço geográfico.

\section{Logística de transportes: fluxos de bens e de serviços}

O desenvolvimento de estudos acerca da logística de transportes nas pesquisas geográficas contribui para a explicação e/ou a compreensão do processo de transformações na infraestrutura econômica e na distribuição das atividades socioeconômicas interconectadas através de serviços, que articulam e viabilizam os fluxos de pessoas, de bens, de serviços e de informações no espaço geográfico. Na argumentação de Ullman (1954), os estudos dos transportes surgiram na ciência geográfica no momento em que os geógrafos passaram a se preocupar com as conexões e com as interações espaciais dos meios de transportes e de comunicações. Essa preocupação levou à compreensão dos processos, fornecendo uma visão renovada e aprofundada das interpretações da circulação constante de mercadorias, de passageiros e de informações na superfície terrestre.

As interações espaciais dos transportes e das comunicações promovem o dinamismo socioeconômico através dos fluxos de mercadorias no cenário do consumo, do comércio e da produção. Os transportes têm a função de viabilizar, espacialmente, os fluxos de matérias-primas, de bens semiacabados, de peças, de equipamentos e de bens acabados da esfera local a internacional. Na logística, o transporte é o serviço operacional de maior destaque na movimentação de mercadorias no mundo dos negócios. Essa argumentação é reforçada por Rodrigues (2003, p. 132), segundo o qual "longe de ser o único, o transporte é o elemento mais visível na cadeia logística, pois diariamente podemos observar caminhões e trens trafegando carregados com mercadorias". Além da visibilidade cotidiana dos fluxos de cargas, a modalidade de transporte pode ser considerada a ligação mais importante entre os serviços logísticos para operacionalização do movimento espacial de mercadorias.

O sistema de transportes é um elemento chave na articulação de atividades separadas espacialmente, pois existe a necessidade de transportar em todos os procedimentos de produção, incluindo a ligação das etapas, desde a aquisição de insumos, o processo de fabricação, a entrega do produto final e o 
retorno de resíduos e de fluxos reversos. Na movimentação de mercadorias, a eficácia e a eficiência do sistema de transporte realizam as interconexões entre produtores e consumidores, na medida em que os clientes e as empresas fazem transações comerciais mais facilmente devido à facilidade de comunicação. Mas na transação comercial, a entrega física da mercadoria adquirida depende dos sistemas de transportes para concluir as operações de entrega do produto ao cliente (TSENG; YUE, 2005). Ao planejar e fazer a gestão da movimentação dos produtos comercializados, Bowersox e Closs (2001) destacam o transporte como uma área operacional da logística. A função dos transportes, segundo Hurst (1974) é criar facilidades para a circulação de mercadorias e desenvolver atividades voltadas também para o setor de serviços. Nesse sentido, destaca-se que é importante fazer uma definição do conceito de transportes.

Após análises dos conceitos de transportes elaborados por Vieira (2001), Rodrigues (2003) e Ludovico (2010), pode-se sintetizar que o transporte é um serviço operacional da logística utilizado para promover os deslocamentos espaciais de pessoas, de mercadorias e também de informações de um lugar para outro no âmbito geográfico urbano, interurbano regional/nacional e internacional. Nesses espaços, a realização dos fluxos depende da infraestrutura viária (fixos), dos modais de transportes disponíveis (fluxos) e dos meios de comunicações, que promovem a articulação entre os diversos tipos de fluxos. A operacionalização dos serviços de transportes pode ser realizada pelo poder público e/ou pela iniciativa privada, através de quaisquer modalidades terrestres, aquaviárias, aérea e até mesmo da combinação dos modais, por meio da implantação da intermodalidade/multimodalidade, nos fluxos de passageiros, de cargas ou misto.

Na movimentação de cargas, o setor de transportes encontra-se subdividido nas modalidades: rodoviário, ferroviário, hidroviário (cabotagem), lacustre, marítimo, dutoviário (oleoduto, gasoduto e mineroduto), aeroviário e inter/multimodal. A Figura 1 demonstra a distribuição das modalidades de transportes aquaviárias, terrestres e aeroviárias, bem como a ligação entre elas através da inter e/ou multimodalidade. 


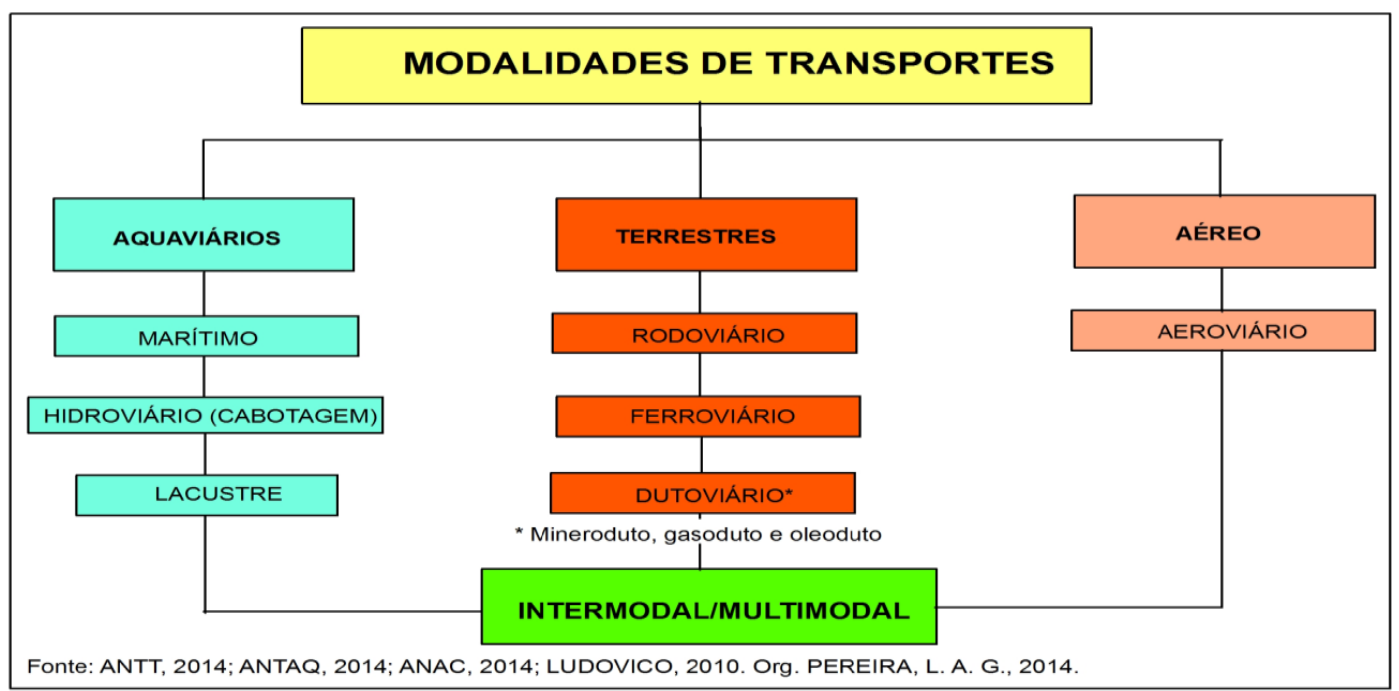

Figura 1. Modalidades de transportes: aquaviários, terrestres, aéreo e intermodal. Fonte: ANTT, 2014;

ANTAQ, 2014; ANAC, 2014; LUDOVICO, 2010. Org. PEREIRA, L. A. G., 2014.

A prestação de serviços através dos modais de transportes terrestres, aquaviários, aéreo e inter/multimodal articula os fluxos de mercadorias na transposição e na superação das distâncias no espaço geográfico. Na atualidade, esses fluxos estão organizados em redes de produção, de comercialização e de informações. A função dos transportes também é oferecer serviços para interconectá-los, uma vez que os fluxos de bens materiais entre os diversos lugares no mundo só acontecem através dos meios de transportes. No processo de interações espaciais dos fluxos de mercadorias, Pereira (2015) definiu a logística de transportes como um segmento da logística responsável pelo planejamento, pelo gerenciamento e pelo controle dos serviços, que auxiliam na tomada de decisão para a escolha do modal de transporte ou dos modais de transportes mais adequados para operacionalizar o sistema de fluxos de mercadorias e de pessoas no espaço geográfico local, regional, nacional e internacional, de forma rápida, eficiente, confiável, segura e de baixo custo. A operacionalização da logística de transportes depende dos terminais e das comunicações/informações para articulação dos fluxos entre fornecedores, produtores, prestadores de serviços, comerciantes e consumidores.

Os transportes mantêm as articulações comerciais para distribuição de mercadorias e promovem as relações socioeconômicas entre as diferentes culturas. E isso tem resultado no aumento do consumo e 
na elevação da qualidade de vida da população em determinadas áreas geográficas. Ao longo da história da humanidade, o comércio foi e é uma atividade socioeconômica desenvolvida com o intuito de oferecer excedentes de produção aos possíveis consumidores. A missão dos meios de transportes é intermediar e interligar o canal de comunicação entre os produtores e os consumidores através da prestação de serviços na distribuição de bens materiais no comércio nacional e internacional (PELETEIRO, 1990).

A expansão do comércio internacional está interligada às melhorias na infraestrutura e nos serviços de transportes. Para Monié (2011), a expansão do comércio internacional exigiu da infraestrutura logística o desenvolvimento de estratégicas com o fim de promover a articulação dos espaços de produção e de consumo no mercado interno e externo. Os sistemas de transportes buscam articular a integração dos fluxos econômicos mundiais entre fornecedores, prestadores de serviços, produtores e consumidores dispersos no espaço geográfico. Isso acontece por meio de uma interconexão entre os nós das redes no processo de organização da produção e dos fluxos de mercadorias. Mas, em caso de imperfeições na infraestrutura e nas conexões dos meios de transportes, os fluxos podem ser comprometidos.

$\mathrm{Na}$ rede logística de transportes, as melhorias ocorreram também nos terminais de transportes modernizados e integrados pelos sistemas de comunicação. Para Rodrigue (1999), as redes de transportes foram otimizadas por meio da sincronização dos terminais de cargas, os quais facilitaram 0 recebimento, o transbordo e a distribuição das mercadorias de forma rápida e contínua, diminuindo o tempo de espera e tornando os transbordos das cargas mais rápidos, de um modal de transporte para outro. A agilidade na sincronização dos terminais de transportes tornou-se uma realidade com o desenvolvimento da comunicação, via telefone e internet. A prestação de serviços especializados nos terminais de transportes deu suporte à viabilização de fluxos ininterruptos de mercadorias na estrutura de consumo e de produção flexível. A Figura 2 mostra o processo de sincronização de uma rede de transportes em uma estrutura de consumo e de produção pós-fordista. 


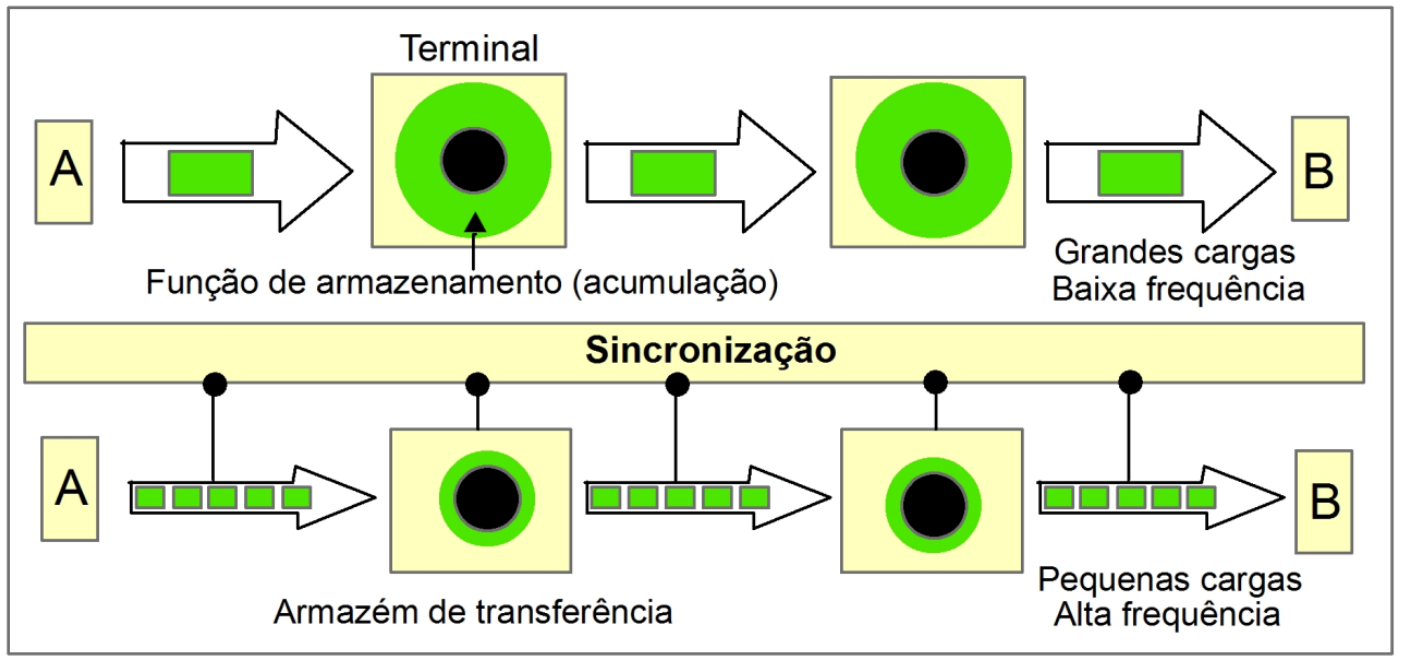

Figura 2. Os efeitos da sincronização em uma cadeia de transportes. Fonte: RODRIGUE, 1999. Adaptado por

PEREIRA, L. A. G., 2014.

Ao se analisar os fluxos em uma rede de consumo e de produção flexível, observa-se a importância dos meios transportes na alta frequência dos fluxos contínuos de pequenos lotes de cargas que ficam pouco armazenados em estoques, integrados pelos sistemas de comunicação. Já na estrutura de produção e de consumo fordista, os produtos ficam armazenados nos terminais e são transportados, em grandes lotes, em baixa frequência. Os terminais de cargas são muito importantes na articulação dos fluxos de transportes nacionais e internacionais. Para Goetz e Rodrigue (1999), os terminais são relevantes para o desempenho dos meios de transportes, na medida em que o funcionamento de portos, de aeroportos, de terminais ferroviários e rodoviários ajuda a sustentar a economia global, interconectando continuamente duas ou mais modalidades em uma rede de transporte intermodal que envolve o percurso desde a origem até o destino do fluxo da mercadoria. O aumento no volume de cargas requer os investimentos na construção, na ampliação e na modernização dos terminais, tornando-se uma preocupação constante de autoridades políticas e de agentes de transportes.

Os terminais de transportes, aqui neste trabalho, denominados de recintos alfandegados de cargas encontram-se localizados nas fronteiras aquaviárias (portos), aéreas (aeroportos) e terrestres (pontos de fronteiras), que possuem o serviço de controlar a entrada e a saída de pessoas, de mercadorias, de veículos, de embarcações e de aeronaves em um determinado país. No Brasil, Bizelli e Barbosa (2000) 
e Rocha (2001) destacam que o território aduaneiro engloba toda a porção territorial, subdividida em zona primária e zona secundária. A zona primária é formada principalmente pela parte interna de portos, de aeroportos e de pontos de fronteiras alfandegados, sendo locais nos quais são controlados os fluxos de mercadorias, de pessoas e de veículos procedentes ou destinados ao exterior. Já a zona secundária abrange todo o restante do território brasileiro, incluindo as áreas terrestres, aquaviárias e aéreas; porém, os recintos alfandegados localizados em zonas secundárias, como é o caso das Estações Aduaneiras Interiores - EADIs (portos secos) -, só podem agilizar o desembaraço de mercadorias originárias ou destinadas ao exterior e enviá-las ou recebê-las de uma zona primária. Ao abordar as importações, as mercadorias se deslocam por transportes nacionais e recintos alfandegados no país parceiro comercial. Desses recintos alfandegados, as mercadorias são embarcadas nas matrizes de transportes internacionais, chegando aos recintos alfandegados brasileiros e seguindo por transportes nacionais até a região norte-mineira. Sendo este o assunto da seção seguinte.

\section{Setores importadores de mercadorias no norte de Minas Gerais: transportes internacionais, recintos alfandegados e transportes nacionais}

Na região norte de Minas Gerais, o início dos fluxos das importações ocorre no exterior, assim como ocorre em todos os lugares, principalmente nos recintos alfandegados do país ou do bloco no qual o norte-mineiro realiza as suas compras. Desses recintos, as mercadorias são embarcadas na matriz de transporte internacional, que traz os produtos até os recintos alfandegados brasileiros. Após o desembarque - no porto, no aeroporto ou no ponto de fronteira -, e depois que ocorre o desembaraço das mercadorias na alfândega, elas seguem para o território norte-mineiro, exclusivamente pelo transporte rodoviário. Os principais produtos importados por setores produtivos no norte de Minas Gerais são: nata de leite, sementes, óleos diversos, coque de petróleo, metais, ácidos diversos, hormonas, medicamentos, corantes, tintas, artigos de higiene, algodão, tecido, garrafas, ferroligas, laminados, rolhas, caldeiras, máquinas, veículos, peças automotivas, eletrodos e aparelhos, dentre outros. 
Ao considerar todos os produtos importados, no período de 2001 a 2012, os empresários do norte de Minas Gerais compraram no exterior um valor total de aproximadamente US\$ 1,4 bilhões de dólares, e uma quantidade, em peso, em torno de 862 milhões de quilogramas (kg). Sendo que 70,2\% dos valores financeiros e 22,0\% da quantidade em quilograma foram oriundos da União Europeia. Do NAFTA foram importados $9,7 \%$ dos valores financeiros, e 44,3\% da quantidade em quilos. No caso da APEC (excluso o NAFTA) importaram 11,9\% dos fluxos financeiros, e 14,7\% da quantidade em quilograma. Enquanto do MERCOSUL, importaram-se 7,1\% dos fluxos financeiros, e 2,4\% da quantidade em quilogramas. Finalizando, de outros blocos/países receberam 5,9\% dos valores financeiros, e 13,4\% da quantidade em peso (vide Mapa 1).

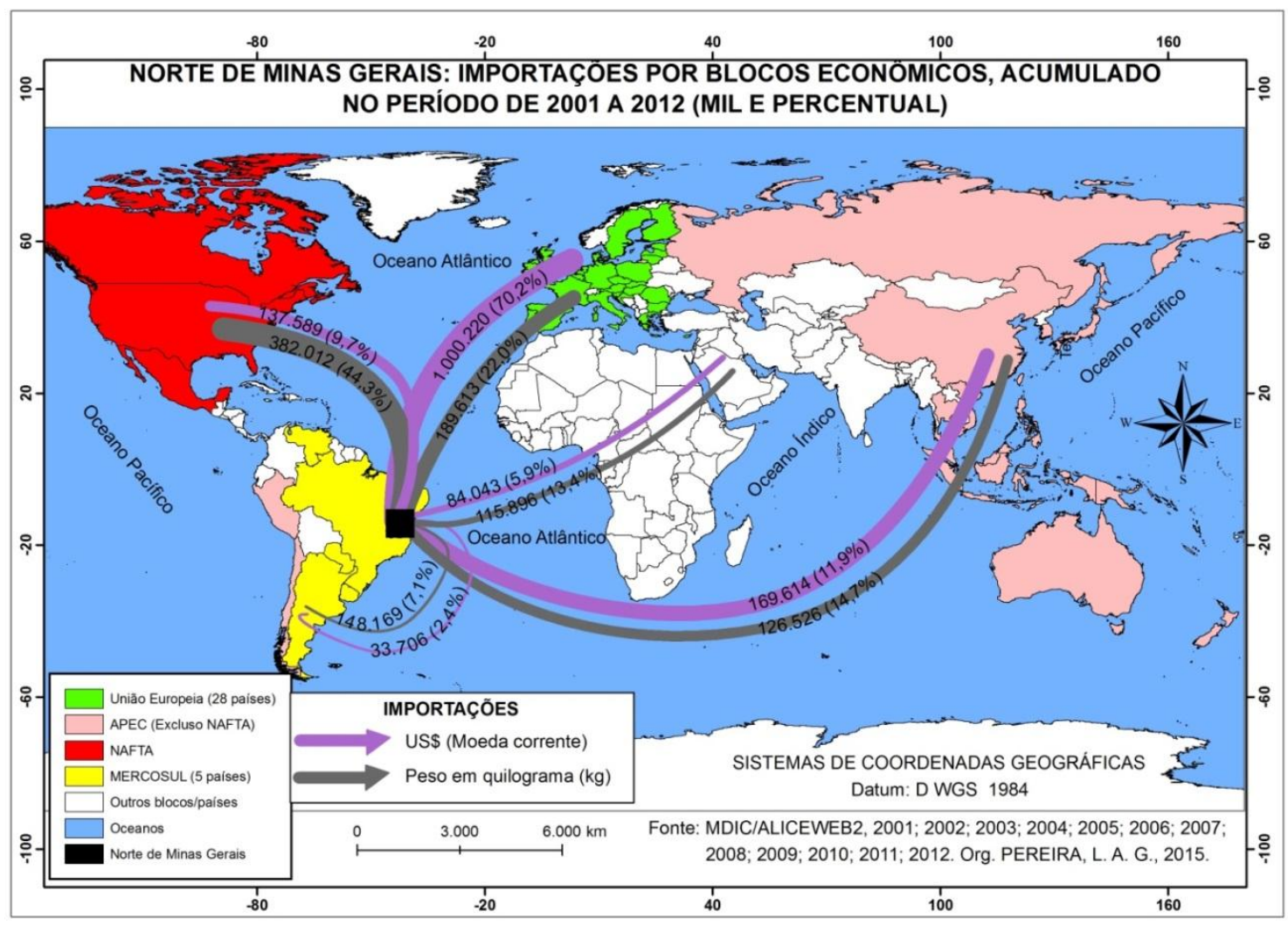

Mapa 1. Norte de Minas Gerais: exportações por blocos econômicos, acumulado no período de 2001 a 2012 (mil e percentual). Fonte: MDIC/ALICEWEB2, 2001; 2002; 2003; 2004; 2005; 2006; 2007; 2008; 2009; 2010;

2011; 2012. Org. PEREIRA, L. A. G., 2014.

$\mathrm{Na}$ análise dos dados das importações originárias dos blocos econômicos, os produtos foram agrupados em categorias setoriais, a partir do Sistema Harmonizado - SH2, que é uma padronização 
internacional para cada tipo de produto nos mercados. Dessa forma, foram criados os setores: de máquinas, aparelhos elétricos e óticos; das indústrias químicas e conexas, dos metais comuns e suas obras, de produtos minerais, de materiais têxteis e suas obras, de produtos plásticos, de obras de pedra e outros setores. Os dados dos fluxos das importações desses setores serão apresentados a seguir.

Ao analisar os dados apresentados na Tabela 1, pode-se considerar que, no geral, os importadores fizeram o uso dos portos e do transporte marítimo para a importação de 69,9\% dos produtos em valores financeiros e de $98,4 \%$ da quantidade em peso. Enquanto os aeroportos e o transporte aéreo movimentaram $31,9 \%$ dos produtos em valores financeiros e $0,2 \%$ da quantidade em quilogramas. Pelos pontos de fronteiras e pelo transporte rodoviário internacional, circulam 1,2\% das importações em valores financeiros e 1,3\% da quantidade em peso; já os outros setores tiveram uma participação muito baixa, que não atingiu $0,1 \%$ dos fluxos.

$\mathrm{Na}$ análise dos fluxos das importações por setores e por modalidades de transportes, o transporte marítimo concentrou $29,4 \%$ de valores financeiros e $10,5 \%$ da quantidade em quilos do setor de máquinas, aparelhos elétricos e óticos. 0 mesmo modal de transporte foi utilizado para transportar 13,5\% dos valores financeiros e 1,8\% da quantidade em peso para o setor das indústrias químicas e conexas. Em seguida, o setor de metais comuns e suas obras, que importou, por meio de transporte marítimo, $12,1 \%$ dos produtos em valores financeiros e $7,6 \%$ de produtos em quilos. 0 setor de produtos minerais fez o uso da modalidade marítima para 3,8\% dos volumes financeiros dos produtos e $75,4 \%$ dos produtos em quantidade quilograma. 0 setor de materiais têxteis e suas obras utilizou 0 transporte marítimo para movimentar $2,3 \%$ dos fluxos em valores financeiros e $0,5 \%$ dos volumes em peso. O setor de obras de pedra usou o modal marítimo para trazer $1,9 \%$ dos bens em valores financeiros e $0,3 \%$ do volume em peso. Os outros setores fizeram a utilização do transporte marítimo para $1,5 \%$ dos produtos movimentados em valores financeiros e $0,5 \%$ dos volumes em peso dos produtos. 


\begin{tabular}{|c|c|c|c|c|c|c|c|c|c|c|c|c|c|c|c|c|}
\hline \multirow[t]{2}{*}{ Setor } & \multicolumn{4}{|c|}{ Marítimo } & \multicolumn{4}{|c|}{ Aéreo } & \multicolumn{4}{|c|}{ Rodoviário } & \multicolumn{4}{|c|}{ Outros } \\
\hline & US\$ & $\%$ USS & Kg & $\% \mathrm{~kg}$ & US\$ & $\begin{array}{c}\% \\
\text { USS }\end{array}$ & $\mathbf{K g}$ & $\% \mathrm{~kg}$ & US\$ & $\%$ USS & $\mathbf{K g}$ & $\% \mathrm{~kg}$ & US\$ & $\begin{array}{c}\% \\
\text { U } \\
\text { SS } \\
\end{array}$ & Kg & $\begin{array}{c}\% \\
\mathrm{~kg}\end{array}$ \\
\hline $\begin{array}{c}\text { Máquinas, } \\
\text { aparelhos } \\
\text { elétricos e } \\
\text { óticos } \\
\end{array}$ & 418.104 & 29,4 & 90.487 & 10,5 & 23.610 & 1,7 & 841 & 0,1 & 4.008 & 0,3 & 188 & 0,0 & 6 & 0 & 0 & 0 \\
\hline $\begin{array}{c}\text { Indústrias } \\
\text { químicas e } \\
\text { conexas } \\
\end{array}$ & 192.532 & 13,5 & 15.387 & 1,8 & 394.394 & 27,7 & 682 & 0,1 & 0,5 & 0,0 & 0,2 & 0,0 & 0 & 0 & 0 & 0 \\
\hline $\begin{array}{c}\text { Metais comuns } \\
\text { e suas obras }\end{array}$ & 171.784 & 12,1 & 65.270 & 7,6 & 11.152 & 0,8 & 241 & 0,0 & 777 & 0,1 & 2.636 & 0,3 & 0 & 0 & 0 & 0 \\
\hline $\begin{array}{l}\text { Produtos } \\
\text { minerais }\end{array}$ & 54.297 & 3,8 & 650.182 & 75,4 & 99 & 0,0 & 11 & 0,0 & 0,3 & 0,0 & 0,9 & 0,0 & 0 & 0 & 0 & 0 \\
\hline $\begin{array}{c}\text { Materiais } \\
\text { têxteis e suas } \\
\text { obras }\end{array}$ & 34.933 & 2,5 & 15.641 & 1,8 & 1.039 & 0,1 & 12 & 0,0 & 10.267 & 0,7 & 7.402 & 0,9 & 0 & 0 & 0 & 0 \\
\hline $\begin{array}{l}\text { Produtos } \\
\text { plásticos }\end{array}$ & 33.013 & 2,3 & 4.408 & 0,5 & 5.073 & 0,4 & 157 & 0,0 & 4 & 0,0 & 10 & 0,0 & 0 & 0 & 0 & 0 \\
\hline Obras de pedra & 26.630 & 1,9 & 2.289 & 0,3 & 966 & 0,1 & 11 & 0,0 & 0,3 & 0,0 & 0 & 0,0 & 0 & 0 & 0 & 0 \\
\hline Outros setores & 21.546 & 1,5 & 4.644 & 0,5 & 18.967 & 1,4 & 107 & 0 & 1.967 & 0,1 & 1.180 & 0,1 & 0 & 0 & 0 & 0 \\
\hline Total & 952.839 & 66,9 & 848.308 & 98,4 & 455.300 & 31,9 & 2.062 & 0,2 & 17.024 & 1,2 & $1.1417,2$ & 1,3 & 6 & 0 & 0 & 0 \\
\hline
\end{tabular}

Tabela 1. Norte de Minas Gerais: importações por setores produtivos e transportes internacionais, no período de

2001 a 2012 (US\$/kg - 1.000). Fonte: MDIC/ALICEWEB2, 2001；2002；2003；2004；2005;

2006；2007；2008；2009；2010；2011；2012. Org. PEREIRA, L. A. G., 2014.

Nas importações, o transporte aéreo internacional foi utilizado pelo setor das indústrias químicas e conexas para circular $27,7 \%$ dos produtos em valores financeiros e $0,1 \%$ da movimentação em quilograma. 0 setor de máquinas, aparelhos elétricos e óticos usam a modalidade aérea nos fluxos de $1,7 \%$ dos valores financeiros e $0,1 \%$ da quantidade em quilos. Os demais setores, conjuntamente, fizeram o uso do transporte aéreo para importar $2 \%$ dos valores financeiros e menos que 0,1\% para a quantidade em quilograma.

O transporte rodoviário internacional tem sido utilizado pelo setor de materiais têxteis e suas obras para a importação de $0,7 \%$ dos volumes financeiros e $0,9 \%$ da quantidade em quilogramas dos produtos. Os demais setores importaram, por via de transporte rodoviário internacional, $0,5 \%$ dos valores financeiros e $0,4 \%$ da quantidade em peso. As outras modalidades de transportes apresentaram uma participação muito baixa, não atingindo $0,1 \%$. 
Os setores importadores também priorizam o transporte marítimo para a movimentação de produtos de baixo valor agregado, tendo, como exemplo, o setor de produtos minerais, que concentra seus fluxos, quase na sua totalidade, na modalidade marítima, uma vez que o seu fluxo financeiro representa somente $3,8 \%$ dos valores financeiros, versus $75,4 \%$ da quantidade em quilos. 0 setor das indústrias químicas e conexas e o das máquinas, aparelhos elétricos e óticos fizeram uso considerável do transporte marítimo por causa do baixo custo operacional, mesmo sendo produtos de alto valor agregado. Novamente, o setor das indústrias químicas e conexas se destacou no uso do transporte aéreo, o que é justificado por possuir produtos de alto valor agregado. 0 transporte rodoviário internacional é pouco utilizado, pois os importadores do norte de Minas Gerais pouco comercializam com os países vizinhos do Brasil, inclusive com o MERCOSUL.

Os fluxos das importações por recintos alfandegados mostram que o porto do Rio de Janeiro (RJ) concentrou $38,2 \%$ dos valores financeiros e $17,4 \%$ da quantidade em peso. 0 porto de Santos foi o segundo recinto alfandegado a receber mercadorias do exterior, somando $10,3 \%$ dos fluxos financeiros e 3,5\% da quantidade em quilo. 0 porto de Vitória (ES) recebeu 6,8\% dos fluxos financeiros e 46,3\% da quantidade em quilograma, seguido pelo porto de Sepetiba (RJ), que movimentou $6,3 \%$ dos fluxos financeiros e $15,2 \%$ da quantidade em quilo. O porto de Cabedelo (PB) recebeu 0,6\% dos valores financeiros e $14,1 \%$ da quantidade em quilograma. Os demais portos, juntos, receberam 1,1\% dos fluxos financeiros e $2 \%$ da quantidade em peso. Os aeroportos também foram utilizados pelos importadores, com destaque para o aeroporto de Confins, que recebeu $28,2 \%$ dos fluxos financeiros e $0,1 \%$ da quantidade em quilograma. Em seguida, o aeroporto de Campinas, que movimentou 5,4\% dos fluxos financeiros e $0,1 \%$ da quantidade em quilos. 0 aeroporto de São Paulo recebeu 1,2\% dos fluxos financeiros e menos de $0,1 \%$ da quantidade em peso. Os demais aeroportos, juntos, receberam importações de $0,7 \%$ dos valores financeiros e menos de 0,1 da quantidade quilograma. Os pontos de fronteiras utilizados nas importações norte-mineiras, conjuntamente, representaram $1,2 \%$ dos fluxos financeiros e 1,3\% da quantidade quilograma (Vide Mapa 2 e Mapa 3). 
$\mathrm{Na}$ análise espacial dos fluxos das mercadorias importadas, o porto do Rio de Janeiro concentrou a circulação do setor de metais comuns e suas obras, das indústrias químicas e conexas e de máquinas, aparelhos elétricos e óticos. O porto de Santos concentrou os fluxos do setor de máquinas, aparelhos elétricos e óticos. Chama a atenção, a movimentação de produtos de baixo valor agregado nos portos de Vitória, Sepetiba e Cabedelo, que receberam fluxos do setor de produtos minerais (coque) com valores financeiros pequenos e uma grande quantidade de peso/volume, tendo como produto importado o coque de petróleo para aquecer fornos da indústria cimenteira em Montes Claros. Outro aspecto importante a ser considerado foi o uso considerável do aeroporto de Confins para os fluxos de produtos das indústrias químicas e conexas, de máquinas, aparelhos elétricos e óticos.

Os empresários importadores, segundo Pereira (2015), acabam buscando os recintos alfandegados portuários e aeroportuários mais próximos da região norte-mineira e aqueles que oferecem os serviços especializados de logística internacional para facilitar os fluxos nas redes de transportes. Nesses recintos, as empresas especializadas em logística internacional oferecem diversos tipos de serviços operacionais para importações - como embalagem de mercadorias, carregamento e descarregamento de contêineres, etc. - e serviços burocráticos para o desembaraço da mercadoria. Após as mercadorias importadas serem desembaraçadas, o transporte rodoviário foi a única modalidade utilizada no escoamento das mercadorias dos recintos alfandegados para as empresas localizadas no norte de Minas Gerais. 


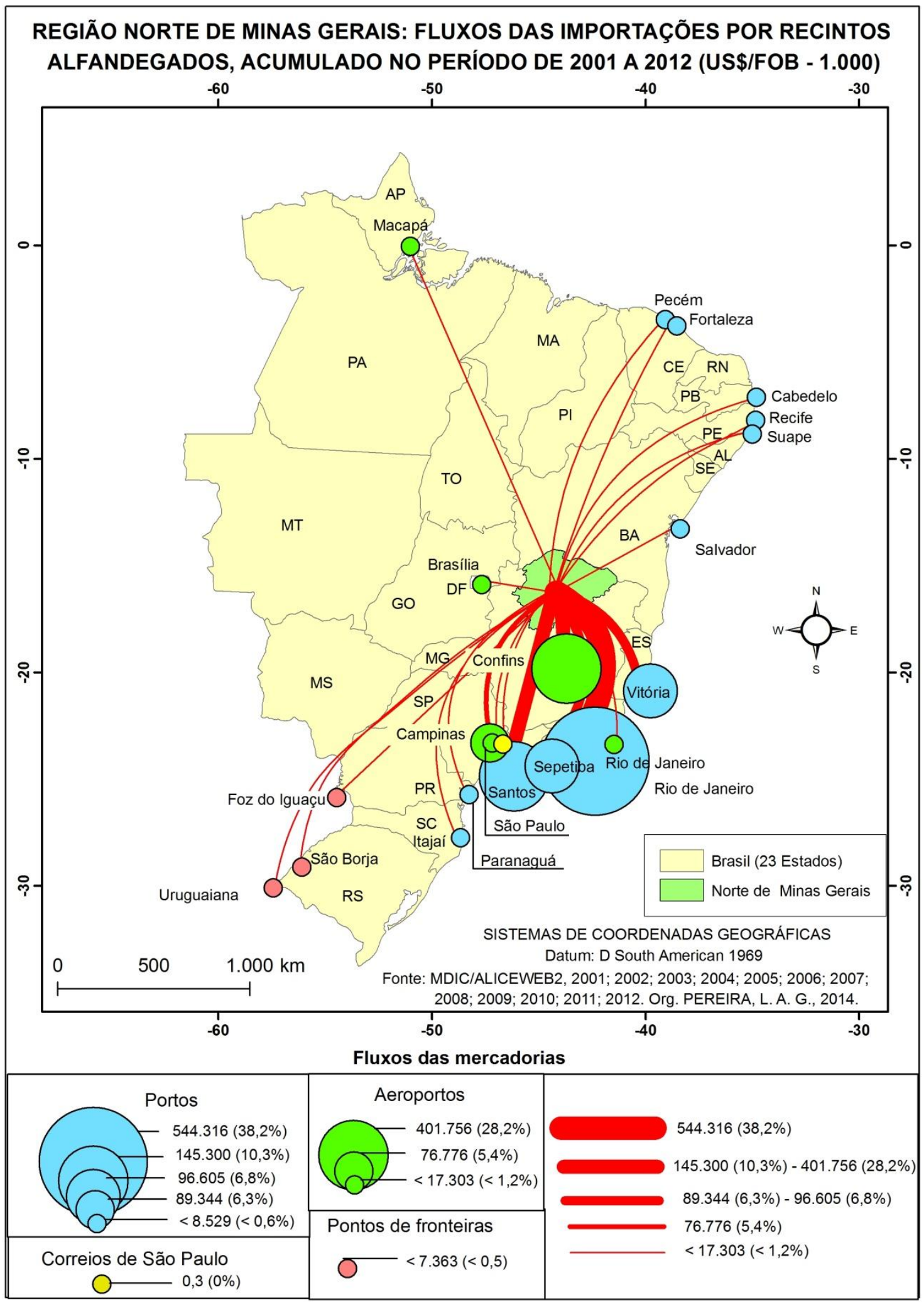

Mapa 2. Região norte de Minas Gerais: fluxos das importações por recintos alfandegados, acumulado no período de 2001 a 2012 (US\$/FOB - 1.000). Fonte: MDIC/ALICEWEB2, 2001; 2002; 2003; 2004; 2005; 2006; 2007; 2008; 2009; 2010; 2011; 2012. Org. PEREIRA, L. A. G., 2014. 


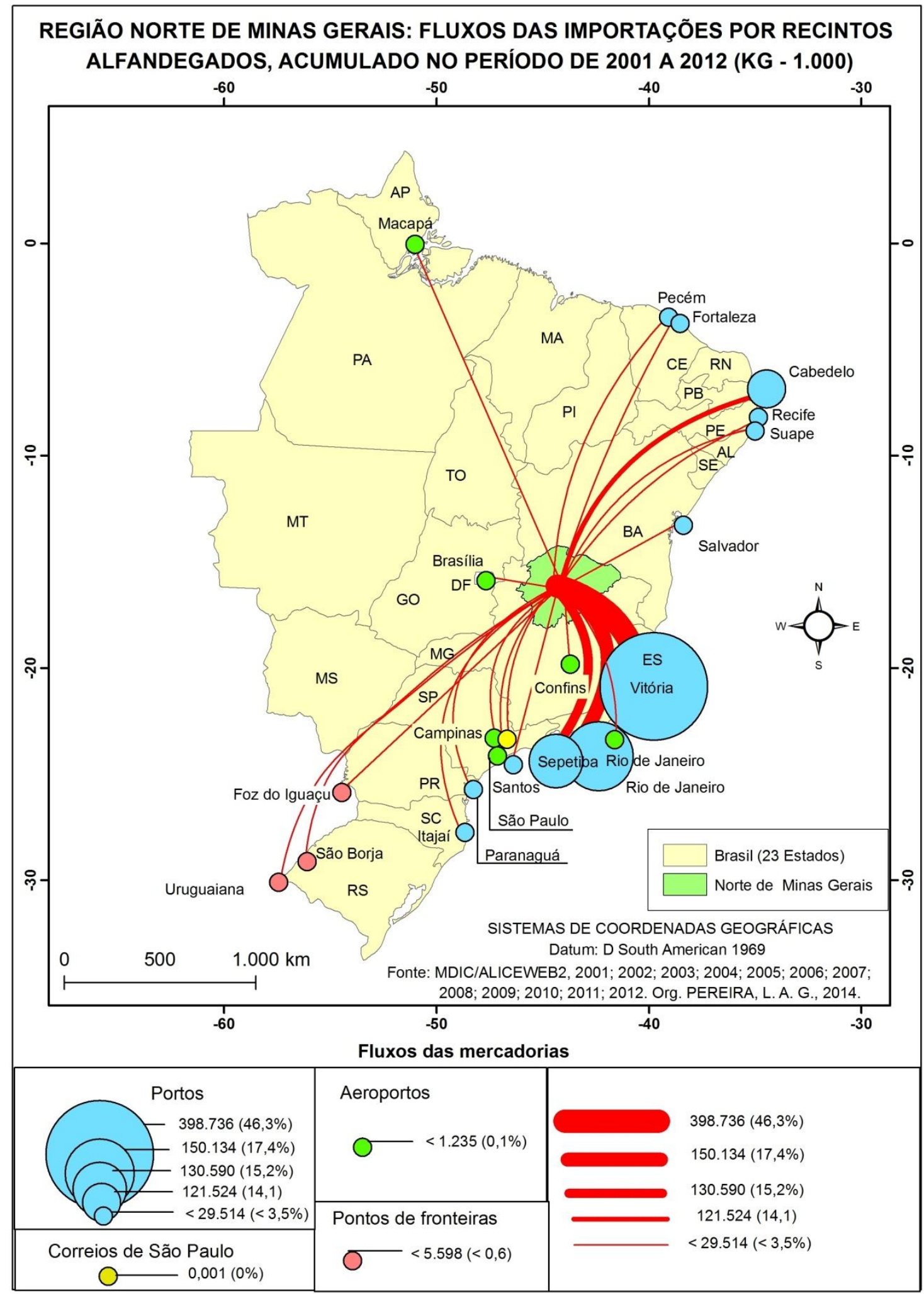

Mapa 3. Região norte de Minas Gerais: fluxos das importações por recintos alfandegados, acumulado no período de 2001 a 2012 (Quilograma/kg - 1.000). Fonte: MDIC/ALICEWEB2, 2001; 2002; 2003; 2004; 2005; 2006; 2007; 2008; 2009; 2010; 2011; 2012. Org. PEREIRA, L. A. G., 2014. 


\section{CONSIDERAÇÕES FINAIS}

A expansão das importações necessita de uma boa rede de infraestrutura e de serviços especializados em transportes, que sejam eficientes, eficazes, rápidos, seguros e preferencialmente de baixo custo para promover a circulação de mercadorias entre os agentes em diversos mercados no espaço geográfico internacional. A logística de transportes, que articula os fluxos de mercadorias importadas entre os empresários e os mercados internacionais, está interconectada e/ou integrada espacialmente por transporte marítimo e portos, por transporte aéreo e aeroportos, por transporte rodoviário e pontos de fronteiras, e por serviços postais e agência de Correios.

A configuração espacial e territorial dos setores importadores e dos mercados internacionais se dá por meio de ligações realizadas através de transportes internacionais, que ligam os recintos alfandegados no exterior aos recintos alfandegados brasileiros. No Brasil, os recintos alfandegados portuários, aeroportuários, pontos de fronteiras recebem as mercadorias importadas para serem nacionalizadas. Após o desembaraço das mercadorias, elas seguem para região norte-mineira somente pelo modal de transporte rodoviário.

As empresas importadoras localizadas no norte de Minas Gerais compram a maioria de suas mercadorias na União Europeia, que representa 70,2\% dos valores financeiros e 22,0\% da quantidade em quilograma. Enquanto do bloco NAFTA são importados 9,7\% dos valores financeiros, e 44,3\% da quantidade em quilos. Os empresários importaram 11,9\% dos fluxos financeiros e 14,7\% da quantidade em quilograma da APEC (excluso o NAFTA). Já do MERCOSUL, importaram-se 7,1\% dos fluxos financeiros, e 2,4\% da quantidade em quilos. E de outros blocos/países receberam 5,9\% dos valores financeiros, e $13,4 \%$ da quantidade em peso. Considerando os fluxos de importações, ao comparar os dados da União Europeia e do NAFTA entre os valores financeiros e a quantidade peso/volume. Observa-se que da União Europeia são importados produtos químicos de alto valor agregado para atender demandas da indústria farmacêutica em Montes Claros. E do NAFTA é importado produto energético mineral, o coque, destinado para indústria cimenteira em Montes Claros. 
No escoamento das importações destinadas ao norte de Minas Gerais predomina a utilização da modalidade marítima e dos portos, com $69,9 \%$ dos fluxos financeiros, e 98,4\% da quantidade em quilograma. O transporte aéreo internacional e os aeroportos representam $31,9 \%$ dos fluxos financeiros e $0,2 \%$ da quantidade em quilograma. E por outras modalidades de transportes circulam menos de 1,5\% das importações em valores financeiros e em quantidade em peso. Os meios de transportes internacionais dependem dos serviços logísticos disponibilizados nos recintos alfandegados brasileiros.

Ao se considerarem os fluxos das importações pelos principais recintos alfandegados, o porto do Rio de Janeiro (RJ) concentrou $38,2 \%$ dos valores financeiros e $17,4 \%$ da quantidade em peso. Seguido pelo porto de Santos, que recebeu $10,3 \%$ dos fluxos financeiros, e $3,5 \%$ da quantidade em peso. 0 porto de Vitória (ES) atraiu 6,8\% dos fluxos financeiros e 46,3\% da quantidade em quilograma. Já o porto de Sepetiba (RJ) escoou 6,3\% dos valores financeiros, e 15,2\% da quantidade em peso. 0 porto de Cabedelo (PB) recebeu 0,6\% dos valores financeiros e 14,1\% da quantidade em quilograma. 0 aeroporto de Confins atraiu $28,2 \%$ dos fluxos financeiros e $0,1 \%$ da quantidade em quilograma. 0 aeroporto de Campinas recebeu 5,4\% das mercadorias em valores financeiros, e $0,1 \%$ da quantidade em quilograma. Todos os pontos de fronteiras representaram 1,2\% dos fluxos financeiros e 1,3\% da quantidade quilograma.

Na logística de transportes utilizada para circulação de mercadorias importadas, o valor agregado do produto ou a urgência na entrega do produto são fatores que influenciam na escolha do modal de transporte para transportá-lo pelos empresários. Os produtos de baixo valor agregado são transportados por transporte marítimo e desembarcados em portos. E os produtos de alto valor agregado circulam por transporte aéreo e são descarregados nos aeroportos. No caso dos países da América do Sul, que fazem fronteira com o Brasil, foram utilizados o transporte rodoviário internacional e os pontos de fronteiras. Geralmente, o empresário escolhe o recinto alfandegado mais próximo da região para o desembaraço da mercadoria e nas regiões dos recintos são contratados os serviços logísticos. A logística de transportes utilizada nos fluxos das importações é complexa e 
dinâmica, exigindo estudos, planejamento e investimentos (públicos e privados) constantes para a sua melhoria.

Apoio financeiro: CAPES

\section{REFERÊNCIAS}

AGÊNCIA NACIONAL DE AVIAÇÃO CIVIL - ANAC. Dados e estatísticas. Brasília: ANAC, 2014. Disponível em: < http://www.anac.gov.br >. Acesso em 13 set. 2014.

AGÊNCIA NACIONAL DE TRANSPORTES TERRESTRES - ANTT. Infraestrutura. Brasília: ANTT, 2014.

Disponível em: < http://www.antt.gov.br $>$. Acesso em 13 set. 2014.

AGÊNCIA NACIONAL DE TRANSPORTES AQUAVIÁRIOS - ANTAQ. Principais portos do Brasil. Brasília: ANTAQ, 2014. Disponível em: <http://www.antaq.gov.br $>$.

Acesso em 13 set. 2014.

ANTUNES JUNIOR, Jose Antonio Valle; KLIEMANN NETO, Francisco Jose; FENSTERSEIFER, Jaime Evaldo. Considerações críticas sobre a evolução das filosofias de administração da produção: do "just-in-case" ao "just-in-time". Revista de Administração de Empresas, São Paulo, v. 29, n. 3, p. 49-64, 1989.

BALLOU, Ronald H. Logística empresarial: transportes, administração de materiais e distribuição física. Tradução de Hugo T. Y. Yoshizaki. São Paulo: Atlas, 1993. 388 p.

Gerenciamento da cadeia de suprimentos/logística empresarial. 5. ed. Tradução de Raul Rubenich. Porto Alegre: Bookman, 2006. 616 p.

BIZELLI, João dos Santos; BARBOSA, Ricardo. Noções básicas de importações. São Paulo: Aduaneiras, 2000.205 p.

BOWERSOX, Donald J.; CLOSS, David J. Logística empresarial: o processo de integração da cadeia de suprimento. Tradução de Equipe do Centro de Estudos em Logística e Adalberto Ferreira das Neves. São Paulo: Atlas, 2001.594 p.

CASTELLS, Manuel. A sociedade em rede. São Paulo: Paz e Terra, 1999. 698 p.

CHRISTOPHER, Martin. Logística e gerenciamento da cadeia de suprimentos. Tradução de Ez2 translate. São Paulo: Cengage Learning, 2011. 332 p.

DAVID, Pierre; STEWART, Richard. Logística internacional. Tradução de Laís Andrade. São Paulo: Cengage Learning, 2010. 416 p.

GOETZ, A. R.; Rodrigue, Jean Paul. Transport Terminals: New Perspectives. Journal of Transport Geography, v. 7, n. 4,

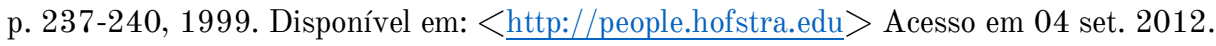

HARVEY, David. Condição pós-moderna: uma pesquisa sobre as origens da mudança cultural. 4. ed. São Paulo: Loyola, 1989. 349 p.

HURST, Michael Eliot. Transportation Geography: Comments and Readings. New York: McGraw Hill, 1974.448 p. 
LARRAÑGA, Félix Alfredo. A gestão logística global. 2. ed. São Paulo: Aduaneiras, 2008.290 p.

LUDOVICO, Nelson. Logística de transportes internacionais. São Paulo: Saraiva, 2010. 221 p.

MINISTÉRIO DO DESENVOLVIMENTO INDÚSTRIA E COMÉRCIO EXTERIOR -MDIC/ALICEWEB2. Importação municípios. Brasília: MDCI, 2012. Disponível em http://aliceweb2.mdic.gov.br/>. Acesso em: 20 mai. 2014.

Importação municípios. Brasília: MDIC, 2011. Disponível em http://aliceweb2.mdic.gov.br/ >. Acesso em: 20 mai. 2014.

2014.

Importação municípios. Brasília: MDIC, 2010. Disponível em http://aliceweb2.mdic.gov.br/>. Acesso em: 20 mai.

Importação municípios. Brasília: MDIC, 2009. Disponível em http://aliceweb2.mdic.gov.br/ $>$. Acesso em: 20 mai. 2014.

Importação municípios. Brasília: MDIC, 2008. Disponível em http://aliceweb2.mdic.gov.br/ $>$. Acesso em: 20 mai. 2014.

Importação municípios. Brasília: MDIC, 2007. Disponível em http://aliceweb2.mdic.gov.br/ $>$. Acesso em: 20 mai. 2014. 2014.

Importação municípios. Brasília: MDIC, 2006. Disponível em http://aliceweb2.mdic.gov.br/>. Acesso em: 20 mai.

Importação municípios. Brasília: MDIC, 2005. Disponível em http://aliceweb2.mdic.gov.br/ $>$. Acesso em: 20 mai. 2014. 2014.

Importação municípios. Brasília: MDIC, 2004. Disponível em http://aliceweb2.mdic.gov.br/ $>$. Acesso em: 20 mai. 2014

Importação municípios. Brasília: MDIC, 2003. Disponível em http://aliceweb2.mdic.gov.br/ $>$. Acesso em: 20 mai. 2014.

Importação municípios. Brasília: MDIC, 2002. Disponível em http://aliceweb2.mdic.gov.br/ $>$. Acesso em: 20 mai.

. Importação municípios. Brasília: MDIC, 2001. Disponível em http://aliceweb2.mdic.gov.br/>. Acesso em: 20 mai. 2014.

MONIÉ, Frédéric. Dinâmicas produtivas, logística e desenvolvimento territorial. In: COSTA, Pierre; VIDEIRA, Sandra Lúcia; FAJARDO, Sérgio (Org.). (RE) leituras da Geografia Econômica. Rio de Janeiro: Letra Capital Editora, 2011. p. 145-167. 193 p.

NOVAES, Antônio Galvão. Logística e gerenciamento da cadeia de distribuição: estratégia, operação e avaliação. 5. ed. Rio de Janeiro: Elsevier, 2001. 409 p.

OHNO, Taiichi. Sistema Toyota de produção: além da produção em larga escala. Porto Alegre: Bookman, 1997.150 p.

PELETEIRO, Rosario Piñeiro. Comercio y transporte. Madrid: Sintesis, 1990. 140 p. 
PEREIRA, Luiz Andrei Gonçalves. Logística de transportes e comércio internacional: os fluxos das exportações e das importações de mercadorias no norte de Minas Gerais. 2015. 219 f. Tese (Doutorado em Geografia) - Programa de PósGraduação em Geografia, Instituto de Geografia, Universidade Federal de Uberlândia, Uberlândia, 2015.

ROCHA, Paulo César Alves. Logística e aduana. São Paulo: Aduaneiras, 2001. 170 p.

RODRIGUE, Jean-Paul. Globalization and the Synchronization of Transport Terminals. In: Journal of Transport Geography, v. 7, n. 4, p. 255-261, 1999.

RODRIGUES, Paulo Roberto Ambrósio. Introdução aos sistemas de transporte no Brasil e à logística internacional. São Paulo: Aduaneiras, 2003. 180 p.

SILVEIRA, Márcio Rogério. Geografia da circulação, transportes e logística: construção epistemológica e perspectivas. In: SILVEIRA, Márcio Rogério (Org.). Circulação, transportes e logística: diferentes perspectivas. São Paulo: Outras Expressões, 2011. p.21-68. 624 p.

As cinco revoluções e evoluções logísticas e seus impactos sobre o território brasileiro. In: SILVEIRA, Márcio Rogério; LAMOSO, Lisandra Pereira; Mourão, Paulo Fernando Cirino. Questões nacionais e regionais do território Brasileiro. São Paulo: Expressão Popular, 2009. 352 p. p.13-42.

TSENG, Yung-yu; YUE, Wen L. The role of transportation in logistics chain. Proceedings of the Eastern Asia Society for Transportation Studies, v. 5, p. 1657-1672, 2005.

ULLMAN, Edward L. Transportation Geography. In: JAMES, Preston E.; JONES, Clarense F. (Ed.). American Geography: Inventory and Prospect. Seattle: Association of American Geographers, Syracuse University Press, 1954. 578p. p. 310-332.

VIEIRA, Guilherme B. Borges. Transporte internacional de cargas. São Paulo: Aduaneiras, 2001. 144 p. 